INDEPENDENT JOURNAL OF MANAGEMENT \& PRODUCTION (IJM\&P)

http://www.ijmp.jor.br

v. 11, n. 7, November - December 2020

ISSN: 2236-269X

DOI: 10.14807/ijmp.v11i7.1206

\title{
ALLOCATING PARTICIPANTS: A MATHEMATICAL MODEL FOR SELECTION PROCESS
}

\author{
Flávio Araújo Lim-Apo \\ Universidade de Brasília, Brazil \\ E-mail: flavio@lim-apo.com \\ Silvia Araújo dos Reis \\ Universidade de Brasília, Brazil \\ E-mail: silviaareis@yahoo.com.br \\ Victor Rafael Rezende Celestino \\ Universidade de Brasília, Brazil \\ E-mail:vrcelestino@unb.br \\ José Márcio Carvalho \\ Universidade de Brasília, Brazil \\ E-mail: jmcarvalho1708@gmail.com
}

Submission: 12/16/2019

Revision: 1/7/2020

Accept: 2/6/2020

\section{ABSTRACT}

Selections, exams, and tests for knowledge assessment frequently require the participant be present on a facility to take a presential test. In 2017, 6.7 Million participants took the biggest Brazilian exam: Exame Nacional do Ensino Médio (ENEM). Logistics is a fundamental key to the execution of these events, responsible to select the locations, allocate each participant in one of a list of possible preselect facilities, and hire temporary staff to apply the tests. Deciding the locations that will be used is a crucial step that determines the two major logistical costs (staff and rent), and a bad decision will directly impact the global costs of the event. Hence, the goal of this work is to elaborate mathematical models using Lingo 17.0 to assist the decision makers to decide which locations to use, including the designation where the participant will take the test, first to minimalize the costs and then maximize the participant service level. The resulting models include multiple complex and specific constraints solved extremely fast and focused on not only providing the best solution, but also automating a manual and time-consuming process. In addition, a trade-off curve between cost and participant service level assists the decision maker to select the best option for different scenarios. 
DOI: 10.14807/ijmp.v11i7.1206

Keywords: Operational Research, Mathematical Modeling, Designation problem, trade-off

\section{INTRODUCTION}

Presential tests for selections, certifications, and knowledge assessment are common worldwide. Brazil has the second largest event in the world when students simultaneous take a presential test, the Exame Nacional do Ensino Médio (ENEM - the National High School Exam), at some facility (BRASIL, 2015). A good grade on the ENEM allows admission into the bests public and private universities.

In 2016, 8,627,194 people registered to take the ENEM, correspond to $4.18 \%$ of the Brazilian population (BRASIL, 2016). This requires an extend logistic strategy to plan the event. To execute the event with efficiency and efficacy, the costs must be minimized because the resources are limited and multiple constraints must be satisfied.

The cost is important to the logistic activity and defines the frequency and which activities should be modernized to provide the best results. Small changes in expensive processes can significantly reduce the cost (BALLOU, 2006).

In 2016, the Centro Brasileiro de Pesquisa em Avaliação e Seleção e de Promoção de Eventos (Cebraspe) held 21 public selection with 1,549,282 participants; 5 selection with 107,386 participants, and applied the ENEM in 14 federative units to 4,109,880 participants. This required hiring 535,312 people to work a temporal staff in positions as coordinator, coordinator's assistant, Room inspector, Room Chief, Operational Support, and others (RELATORIO DE GESTÃO, 2016).

Logistics Coordination is responsible to select the facilities that will be used, to hire staff, empower and train staff, allocate the participants and the staff in the facilities, and plan the transport of the tests.

This paper aim to develop a mathematical model that assists the decision maker to allocate the participants in the available facilities with the goal of minimizing the operational logistic cost and optimizing the participant service level.

These events normally include thousands of participants and dozens of locates. To take the test, participants must go to the facility that they were assigned to. The participant service level is measured as the distance that they need to travel between their house and where they are assigned. Beyond the benefit to the participant, as people will travel a shorter overall distance, toxic gas emissions from participant's vehicles may be a reduced. 
DOI: 10.14807/ijmp.v11i7.1206

\section{THEORETICAL BACKGROUND}

Although development has occurred in the use of computational systems and in the system that helps decision makers, managers may not always know how to use them or that new technologies even exists. The use of these tools can reduce the global cost and allow processes to become more effective (BOWERSOX et al., 2014). Organizations seek to reach new solutions to help in the decision making. Continuous improvement of quality and productivity is a central point to management (GOLDBARG, 2000).

Globalization, development of new information services and more flexible process lead customers to choose a faster solution. Hence, customers expect new improvements in how services are provided (BALLOU, 2006).

\subsection{Trade-off}

A central point of this work is the trade-off of choosing one item over another by weighing the advantages of each. As companies are inserted in a globalized world, the knowledge of trade-off is necessary, because organizations constantly need to choose an alternative between several options.

Nishi et al. (2016) demonstrated a trade-off between cost and service level, and that it was possible to reduce the total cost and still maintain an intended service level. The calculation for the definition of the trade-off curve presents the possibility of choosing between variables and the choice of one item over another may result in a reduction or increase of the objective function.

According to Winston and Goldberg (2004), the trade-off curve for two variables can be obtained in three steps. First, the model must be defined, after it is necessary to discover the extreme point of the first and then the second variable.

The mathematical model should, through its equations, verify which trade-offs will be performed to optimize the defined objectives.

\subsection{Operational Research}

Modeling a problem is an Operational Research activity. Moore and Weatherford (2005) states that there is a difference between a real problem and a model. In the real world, the decision maker decides about the management problem, sometimes using just intuition. To create a model, a symbolic world is needed, because the model cannot have and predict all specificities that might occur. 
DOI: 10.14807/ijmp.v11i7.1206

Thus, in the model, the main core of the problem must be abstracted, analyzed to produce results, and interpreted to make a finally decision.

It is important to create the model in a symbolic world. Lachtermacher (2007) presents the certainty hypothesis, which assumes that the parameters that the mathematical model uses are known constants. Sensitivity analysis becomes necessary to view the impact that changing the parameters will have on the outcome and decision variables.

Beyond the aspect that in the real world unplanned changes can happen in value parameters and constants, another important aspect is to know the organization wants not just the optional solution, but instead the bests solutions. Sometimes a high cost solution is preferred due to another gain, for example an easier solution to implant or a gain to the customers.

\section{METHODS AND RESEARCH TECHNIQUES}

According Gil (2008), veracity of the facts is a goal of science; therefore, the information must be checked to guarantee adequate reliability and validity of the study. Hence. We will use the tactics of Yin (2010) to present and register data.

This article reports an applied research using a case study consisting in a deep and exhaustive research that provides a broad and detailed knowledge of an activity (GIL, 1991). Applied research involves the creation of knowledge for the application of specific problem solving (MORESI, 2003).

In the literature review carried out by the authors of this work, no published articles were found with the theme of elaborating a mathematical model for the allocation of participants. Although no studies similar in scope with operational research were found, Lima and Lima Filho (2010) and Arraes (2016) discussed process improvement topics at the Centro de Seleção e de Promoção de Eventos da Universidade de Brasília (CESPE/UnB) and Cebraspe.

The major part of the data used in this study came from Cebraspe's public documents and additional information was provided by interviews with Cebraspe’s Logistics employees.

Belfiore and Fávero (2013) cite three major elements for a mathematical model: the delimitation of decision variables and parameters; the objective function; and the restrictions.

The first step is to know how the costs of an applications occur, defining the rent of the locations, the price to hire staff, the rule to pay staff, and how the participants can be arranged in the facilities. 
DOI: 10.14807/ijmp.v11i7.1206

Hiring staff involves some specific rules: some functions are due to the total number of participants at the location, others involve the quantity of room used, and others are about the number of participants in each room. This happen because some functions are responsible to act at the facility and others are responsible for be in the room with the participants.

Other information extremely important to measure the participant service level is distance between the participant and the test site. We were only provided the address of the participant and the address of the facility, but not the distance between the participant and the facility.

To solve this situation, we used Google Maps API service, to transform address information to latitude and longitude information, which makes it possible to determine the distance between where the participant lives and all test locations.

Google Maps Geocoding API is a service that transforms address information into a latitude and longitude. Then Google Maps Distance Matrix API can measure the distance between two geographic locations using the car transport mode. This means that the distance used here is a real distance and not only a straight line from one point to another that ignores streets, lakes, rivers, and mountains.

Google Maps API is a service that returns the same information as a search using Google Maps on the web or the phone, the major difference is the ability to automatize multiples searches, to automatize the process instead of doing it manually. To automatize this step, we created a Python script to capture the JSON file that the API returns and saves the information.

Once all the required information is obtained, the next step is to start the mathematical modeling of the problem.

\subsection{LINGO}

To solve the models will be used the software LINGO 17.0 using an EDUCATIONAL LICENSE. LINGO has a mathematical language for problem optimization, whether linear, integer, or nonlinear, and has the particularity of solving a wide range of problems extremely fast, as well as its easy user interface and integration with Excel Spreadsheets. (HILLIER; LIEBERMAN, 2012). Nixon (2016) states that LINGO software is a consolidated tool that can perform calculations for the optimization of nonlinear problems. 
DOI: 10.14807/ijmp.v11i7.1206

According to Winston and Goldberg (2004), LINGO and LINDO are problem-solving language operational research resolution programs that allow thousands of variables, parameters, and objective function to be used in mathematical models, the software is from Lindo Systems, Inc.

\section{METHODS AND RESEARCH TECHNIQUES}

Three mathematical models were developed: the first maximizes the participant service level by reducing the distance traveled; the second minimize the global costs; and the third is a mixture of the first two to develop a trade-off curve of cost versus level of service.

\subsection{Model 1 - Mathematical model to maximize participant service level}

A linear programming type model was proposed to minimize the distance traveled by candidates, from residence to test venues.

This model is associated with an assignment model as designated personnel cannot be divided (MOORE; WEATHERFORD, 2005), so each participant must be allocated to exactly one coordination. Along with the assignment model, the model seeks to allocate the person in a coordination with the objective of reducing the global traveled distance, associating it as a transportation model (HILLIER; LIEBERMAN, 2012).

Descriptions of sets, in Table 1, parameters, in Table 2, and variables, in Table 3, follow below.

Table 1: Table of Sets

\begin{tabular}{|c|c|}
\hline Sets & Description \\
\hline P & Participants \\
\hline C & Coordinations \\
\hline
\end{tabular}

Table 2: Table of Parameters

\begin{tabular}{|c|c|}
\hline Parameters & Description \\
\hline limit $_{c}$ & Maximum number of participants for coordination $c$ \\
\hline distance $_{p c}$ & Distance between participant $p$ and coordination $c$ \\
\hline
\end{tabular}

Table 3: Table of Variable

\begin{tabular}{|c|c|}
\hline Variable & Description \\
\hline assign $_{p c}$ & Assignment of the participant $p$ to the institution $c$ \\
\hline
\end{tabular}

Objective function:

$$
\operatorname{Minimize}=\sum_{p, c} \operatorname{distance}(p, c) * \operatorname{assign}(p, c)
$$

Restrictions: 
DOI: $10.14807 /$ ijmp.v11i7.1206

$$
\begin{array}{cc}
\sum_{c} \operatorname{assign}(p, c)=1 & \forall p \in P \\
\sum_{p} \operatorname{assign}(p, c) \leq \operatorname{limit}(c) & \forall c \in C
\end{array}
$$

The objective function (1) has the goal of minimizing global distance to be traveled. The first restriction (2) is used such as the participant is allocated in exactly one coordination, while the second (3) allows the assignment up to the maximum number of participants allowed for each coordination.

\subsection{Model 2: Mathematical Model for costs minimization}

The cost minimization model is of mixed binary integer programming type. The costs are minimized by participants allocation at venues that result in lower establishments and personnel assignment costs. Sets, parameters, and variables are described, respectively, in following Tables 4, 5, and 6.

Table 4: Table of Sets

\begin{tabular}{|c|l|}
\hline Sets & \\
\hline$I$ & Coordination \\
\hline$J$ & Room \\
\hline$F$ & Coordinating functions hired by number of rooms in coordination \\
\hline$G$ & Coordinating functions hired by number of candidates in coordination \\
\hline$H$ & Room functions hired by number of candidates in the room \\
\hline
\end{tabular}

Table 5: Table of Parameters

\begin{tabular}{|c|l|}
\hline Parameters & \multicolumn{1}{c|}{ Description } \\
\hline applicants & Total applicants for the event \\
\hline capacity $_{i, j}$ & Room capacity for participants in room $j$ of coordination $i$ \\
\hline room_reserve & Cost of leasing by number of candidates in coordination $i$ \\
\hline remun_funct_coord_room $f_{f}$ & $\begin{array}{l}\text { Rumber of rooms in reserve by coordination } \\
\text { the coordination }\end{array}$ \\
\hline remun_funct_coord_part \\
\hline remun_funct_room_part
\end{tabular}

Table 6: Table of Variable

\begin{tabular}{|c|l|}
\hline Variable & \multicolumn{1}{c|}{ Description } \\
\hline assign $_{i j}$ & $\begin{array}{l}\text { Integer variable of the number of designated participants for each room } \\
\text { of each institution. }\end{array}$ \\
\hline assign_coord $_{i}$ & Integer variable of the number of participants allocated by coordination \\
\hline capacity_coord $_{i}$ & Integer variable of participants capacity by coordination \\
\hline
\end{tabular}


INDEPENDENT JOURNAL OF MANAGEMENT \& PRODUCTION (IJM\&P)

http://www.ijmp.jor.br

v. 11, n. 7, November - December 2020

ISSN: 2236-269X

DOI: 10.14807/ijmp.v11i7.1206

\begin{tabular}{|c|c|}
\hline 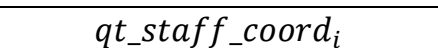 & Integer variable of the number of staff by coordination \\
\hline room_avail $l_{i}$ & Integer variable of the number of rooms available by coordination \\
\hline room_used $_{i}$ & $\begin{array}{l}\text { Integer variable of the number of rooms with assigned participants by } \\
\text { coordination }\end{array}$ \\
\hline cost_lease_i & Continuous variable of leasing cost by coordination \\
\hline cost_staff $f_{i}$ & Continuous variable of the cost of staff by coordination \\
\hline cost_coord_staff_room $_{i}$ & $\begin{array}{l}\text { Continuous variable of staff cost in coordinating functions hired by the } \\
\text { number of rooms in coordination by coordination }\end{array}$ \\
\hline cost_coord_staff_part $_{i}$ & $\begin{array}{l}\text { Continuous variable of staff cost in coordinating functions hired by the } \\
\text { number of participants in coordination by coordination }\end{array}$ \\
\hline cost_room_staff_part ${ }_{i}$ & $\begin{array}{l}\text { Continuous variable of staff cost in coordinating functions hired by the } \\
\text { number of participants in the room by coordination }\end{array}$ \\
\hline capacity $_{i, j}$ & Integer variable of participants capacity in room $j$ of coordination $i$ \\
\hline avail_room $_{i, j}$ & Binary variable to check if the room is available \\
\hline$u_{s e \_r o o m}$ & Binary variable to verify that the room has candidates assigned \\
\hline$q t_{-} s t a f f \_c o o r d \_r o o m_{f}$ & $\begin{array}{l}\text { Integer variable of the amount of staff in coordinating functions hired by } \\
\text { number of rooms in coordination by coordination }\end{array}$ \\
\hline$q t_{-}$staff_coord_part ${ }_{g}$ & $\begin{array}{l}\text { Integer variable of the amount of staff in coordinating functions hired by } \\
\text { the number of participants in coordination by coordination }\end{array}$ \\
\hline$q t_{-}$staff_room_part ${ }_{h}$ & $\begin{array}{l}\text { Integer variable of the amount of staff in coordinating functions hired by } \\
\text { the number of participants in the room by coordination }\end{array}$ \\
\hline staff_funct_coord_room ${ }_{f, i}$ & $\begin{array}{l}\text { Binary variable to verify if staff with coordination function } f \text { hired by } \\
\text { number of rooms is eligible in coordination } i\end{array}$ \\
\hline staff_funct_coord_part ${ }_{g, i}$ & $\begin{array}{l}\text { Binary variable to verify if staff with coordination function } g \text { hired by } \\
\text { the number of participants is eligible in coordination } i\end{array}$ \\
\hline staff_funct_room_part $_{h, i, j}$ & $\begin{array}{l}\text { Binary variable to verify if staff with room function } h \text { hired by the } \\
\text { number of participants is eligible in the room } j \text { of coordination } i\end{array}$ \\
\hline$q t \_t o t a l \_s t a f f$ & Integer variable of total amount of staff \\
\hline cost_total_lease & Continuous variable of the total cost of leasing \\
\hline cost_total_staff & Continuous variable of the total cost of personnel \\
\hline
\end{tabular}

Objective function:

$$
\text { Minimize }=\text { cost_total_lease }+ \text { cost_total_staff }
$$

Restrictions:

$$
\sum_{j} \operatorname{assign}(i, j) * \operatorname{lease}(i)=\text { cost_lease }_{(}(i)
$$

$\forall i \in I$

$$
\sum_{f} s t a f f_{-} f u n c t \_c o o r d \_r o o m(f, i) * r e m u n_{-} f u n c t \_c o o r d \_r o o m(f)
$$

$$
\begin{gathered}
\sum_{j} \text { staff_funct_coord_part }(g, i) * r e m u n_{-} f u n c t \_c o o r d \_p a r t(g) \\
=\text { cost_coord_staff_part }(i)
\end{gathered}
$$

$$
\begin{gathered}
\sum_{j} \text { staff_funct_room_part }(h, i, j) * r e m u n_{-} f u n c t \_r o o m \_p a r t(h) \\
=\text { cost_room_staff_part }(i) \\
\text { cost_coord_staff_room }(i)+\text { cost_coord_staff_part }(i) \\
+ \text { cost_room_staff_part }(i)=\text { cost_staff }(i) \\
\sum_{j} \text { capacity }(i, j) \geq \text { avail_room }(i, j)
\end{gathered}
$$

$$
\forall \boldsymbol{i} \in \boldsymbol{I}
$$

$$
\forall i \in I
$$




$$
\begin{aligned}
& \sum_{j} \operatorname{capacity}(i, j) \leq M * \text { avail_room }(i, j) \quad \forall i \in I, \forall j \in J \\
& \sum_{j} \text { use_room }(i, j)=\operatorname{room} \_u s e d(i) \quad \forall i \in I \\
& \sum_{j} \text { avail_room }(i, j)=\text { room_avail }(i) \quad \forall i \in I \\
& \text { room_avail }(i)-r u l e_{-} f u n c t+c o o r d \_r o o m(f) \\
& \leq M * s t a f f_{-} \text {funct_coord_room }(f, i) \\
& \text { assign_coord }(i)-r u l e_{-} f u n c t \text { coord_part }(g) \\
& \leq M * \text { staff_funct_coord_part }(g, i) \quad \forall g \in G, \forall i \in I \\
& \operatorname{assign}(i, j)-\text { rule_funct_room_part }(h) \\
& \leq M * \text { staff_funct_room_part }(h, i, j) \quad \in I, \forall j \in J \\
& \sum_{i, j} \operatorname{assign}(i, j)=\operatorname{applicants}(1) \\
& \operatorname{assign}(i, j) \leq \operatorname{capacity}(i, j) \\
& \sum_{f} \text { staff_funct_coord_room }(f, i) \\
& \begin{array}{l}
+\sum_{g} \text { staff_funct_coord_part }(g, i) \\
+\sum_{h, i, j} \text { staff_funct_room_part }(h, i, j)
\end{array} \\
& \sum_{i} q t_{-} s t a f f_{-} \text {coord }(i)=q t_{-} \text {total_staff }(1) \\
& \forall \boldsymbol{f} \in \boldsymbol{F}, \forall \boldsymbol{i} \in \boldsymbol{I} \\
& \forall \boldsymbol{h} \in \boldsymbol{H}, \forall \boldsymbol{i} \\
& \forall i \in I, \forall j \in J
\end{aligned}
$$

The objective function 4 has the goal to minimize global cost of the application, which is the sum of the costs for the lease and staff. Restriction 5 creates the cost of leasing in each location. Restrictions 6, 7, and 8 determine the cost by coordination for each type of personnel hiring. Equation 9 sets the total cost of personnel by coordination. The combination of restrictions 10 and 11 determines that the variable avail_room $(i, j)$ is equal to 1 when the room has the capacity to have at least one participant assigned. The ' $M$ ' characterizes a very large number, larger than the capacity of a room.

Equation 12 informs the number of rooms used in the coordination, while 13 reports how many rooms are available by coordination. Restrictions 14, 15, and 16 set the hiring of 
DOI: 10.14807/ijmp.v11i7.1206

personnel in functions $f$ related to hiring by quantity of rooms in a coordination, functions $g$ is related to the number of participants in coordination and staff in functions $\mathrm{h}$ related to the number of participants in room $i$ of coordination $j$, respectively.

The number of applicants must be the same as the sum of the assigned participants, represented in inequality 17 . The assignment of participants in the rooms must comply with room capacity, in accordance with restriction 18. Restriction 19 sets the amount of personnel by coordination. Restriction 20 informs the total amount of personnel. Equations 21, 22, and 23 sum the number of personnel hired by function, coordination, and room group, for each type of function. The result is the number of personnel for each contracting function.

Because of security issues, a few reserve rooms for each coordination is mandatory in all events, in case some student must be transferred, therefore, restriction 24 ensures that a number of reserve rooms is met.

Equation 25, 26, and 27 sum the capacity of each coordination, the quantitative of participants in each coordination, and the maximum number of participants that can be allocated for the scenario.

\subsection{Performance}

An example with random data was used, assigning 2,000 participants in up to 7 coordinations, each with distinct assignment capacity and leasing cost, with a total of 16,000 variables and 2,008 constraints.

Problem solving occurred after 2,000 interactions and 0.29 Seconds for Model 1 with 3,722 interactions and 0.81 seconds for Model 2 with LINGO 17.0 software (Educational License), by means of Simplex Primal. The problem was run on a computer with Windows 7 operating system, Intel Core i3-4170 @ 3.70 GHz processor and 12 GB RAM Memory.

\subsection{Model 3 - Trade-Off Curve}

One of the main challenges of a company, according to Hijjar (2000), is to identify of possible trade-offs that can reduce costs related to maintain a satisfactory customer service level.

In this work, models 1 and 2 were grouped to generate a trade-off curve. Model 1 objective function, which maximizes the level of service measured by distance traveled between participant's residence and assigned coordination, became a restriction for Model 2 . 
DOI: 10.14807/ijmp.v11i7.1206

$$
\sum_{p, c} \operatorname{travel}(p, c) * \operatorname{assugn}(p, c) \leq X
$$

The new Model 3 replicates Model 2 but with a minimum level of service to be met. Restriction 28 determines that the total distance traveled by participants must be less or equal to a value $X$, defined by the decision maker. Furthermore, restriction 2 was changed to:

$$
\sum_{p} \operatorname{assign}(p, c) \leq \text { assign_coord }(c) \quad \forall c \in C
$$

Variable "limit(c)" has been replaced for "assign_coord(c)".

To construct the trade-off curve, it is necessary to run Model 3 with several values for the desired level of service $(X)$, in accordance with equation (28).

The first step for a trade-off curve needs to know what values of $X$ should be used. To do this, the model was solved with the minimum value of distance to be travel, the value was 10,365 KM with total cost of R \$33,890 which equals 5.183 KM and R\$ 16.95 per participant. The second step was to discover the minimum that this event could have, in the case it is a total cost of R\$25,375 which equals R\$ 12.69 per participant.

As 10,365 kilometers were the total distance for 2,000 participants, a 500 kilometers variation results in an increase of 250 meters per person. Thus, we need to know the cost for 10,500 kilometers, 11,000 kilometers, 11,500 kilometers until reaching the minimum value of global cost of $\mathrm{R} \$ 25,375$, this resulted in solving the model 14 times changing the value of $X$, with results present in Table 7 and Image 1.

Table 7: Distance versus cost

\begin{tabular}{c|c}
\hline Distance (KM) & Cost \\
\hline 5.183 & $\mathrm{R} \$ 16.95$ \\
5.185 & $\mathrm{R} \$ 16.76$ \\
5.190 & $\mathrm{R} \$ 15.96$ \\
5.200 & $\mathrm{R} \$ 15.84$ \\
5.250 & $\mathrm{R} \$ 15.57$ \\
5.500 & $\mathrm{R} \$ 14.63$ \\
5.750 & $\mathrm{R} \$ 14.45$ \\
6.000 & $\mathrm{R} \$ 13.80$ \\
6.250 & $\mathrm{R} \$ 13.57$ \\
6.500 & $\mathrm{R} \$ 13.41$ \\
6.750 & $\mathrm{R} \$ 13.16$ \\
7.000 & $\mathrm{R} \$ 12.91$ \\
7.250 & $\mathrm{R} \$ 12.91$ \\
7.500 & $\mathrm{R} \$ 12.91$ \\
7.750 & $\mathrm{R} \$ 12.91$ \\
8.000 & $\mathrm{R} \$ 12.91$ \\
8.250 & $\mathrm{R} \$ 12.69$
\end{tabular}

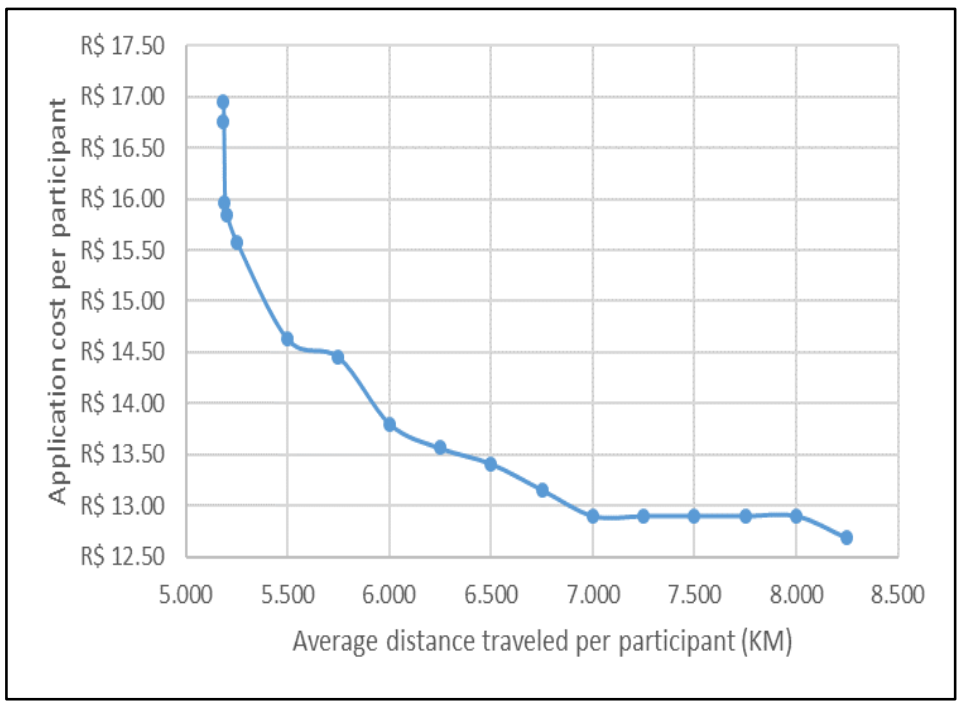

Image 1: Trade-off curve 
DOI: 10.14807/ijmp.v11i7.1206

As showed in Image 1, a gap of $\mathrm{R} \$ 1.37$ exists in cost between average distance traveled per participant (KM) 5.183 and 5.25, to discover how the trade-off curve comports in this range 3 points of 10,370; 10,380; and 10,400 were add. Hence, the trade-off curve has 17 points going from a cost per participant of R 16.95 with a distance of 5.183 kilometer up to a cost of $\mathrm{R} \$$ 12.69 with a distance of 8.250 kilometers, with results showed in Table 7.

The information in Table 7 helps the decision maker to choose the best option for the organization. In events that the company has more budget, it can choose an option that reduces the distance to be traveled and increases the level of service. However, where some contingency in the costs is needed, the organization can choose for a lowest level of service with a lower cost.

\section{CONCLUDING AND RECOMMENDATIONS REMARKS}

The models were successful to provide the information to allocate the participants in the facilities and provide a trade-off curve allowing the decision maker to choose the best combination between the costs and the participant's level of service for the specific scenarios. The trade-off curve allows the visualization of what happens when one option is chosen over another.

A logistic organization has considerable costs with its logistics activities. In a globalized and competitive world, a company must always keep trying to improve its process and activities, reducing costs and time to process the data available to make the best solution for each scenario.

Managers are always looking for opportunities to optimize process and activities, but in some cases, they do not have the knowledge about or how to use new solutions. This paper demonstrated the use of a mathematical modeling in an organization, allowing this to be replicated in another company or/and in another kind of process.

The model was developed using the software Lingo 17.0 and simulating with previous events. The expected cost reduction is between $5 \%$ and $25 \%$, depending on the size of the applications and specific scenarios, because this is a model with multiple specific constraints. In addition to cost savings, it significantly reduced time to obtain the optimal solution. The new model can obtain the optimal solution in one second, something that is impossible manually.

In a simulation with 2,000 participants, it was possible to reduce by $36.95 \%$ the global distance travelled by the candidates, from 20,231.81 to 12,756.88 kilometers. Optimize distance to be traveled also reduces emissions of pollutant gases from vehicles that transport 
DOI: 10.14807/ijmp.v11i7.1206

the participants. The optimum solution in this scenario was $46.60 \%$ better than the worst-case scenario.

Finally, this article showed the gains that an implementation of a mathematical model with use of Operational Research tools can have when introduced in a company that has employed a manual process, demonstrating that improvements in productivity happen with the use of best practices. This research also contributes to scientific knowledge presenting an applied model with a case study still unprecedented in academic publications.

Future studies may adjust the mathematical model for the allocation of participants, minimizing the cost to be used to assist the allocation of personnel who are hired to apply the test. In addition, studies can measure the reduction of emissions of toxic gases and pollutants with the application of the model.

\section{REFERENCES}

BALLOU, R. H. (2006) Gerenciamento da Cadeia de Suprimentos: Logística Empresarial. Bookman Editora.

BELFIORE, P.; FÁVERO, L. P. (2013) Pesquisa Operacional para cursos de Engenharia. Elsevier Brasil.

BRASIL. Ministério da Educação. ENEM 2015: A segunda maior prova de acesso ao ensino superior do mundo. Disponível em: <http://portal.mec.gov.br/component/content/article/418noticias/enem-946573306/31151-a-segunda-maior-prova-de-acesso-ao-ensino-superior-domundo?Itemid=164>. Access: 27th November, 2019.

BRASIL. Ministério da Educação. MEC anuncia mais de 8,6 milhões de estudantes inscritos no Enem 2016. Available: < http://www.brasil.gov.br/educacao/2016/05/mecanuncia-mais-de-8-6-milhoes-de-estudantes-inscritos-no-enem-2016>. Access: $\quad$ 27th November, 2019.

BOWERSOX, D. J. et al. (2014) Gestão logística da cadeia de suprimentos. AMGH Editora, 2014.

GIL, A. C. (1991) Como elaborar projetos de pesquisa. São Paulo: Atlas, 1991.

GIL, A. C. (2008) Métodos e técnicas de pesquisa social. 6. ed. Ediitora Atlas SA, 2008.

GOLDBARG, M. C.; LUNA, H. P. L. (2000) Programação linear e otimização combinatória: modelos e algoritmos. Rio de Janeiro: Campus, v. 1, p. 639.

HIJJAR, M. F. (2000) Segmentação de mercado para diferenciação dos serviços logísticos. In: Logística empresarial: a perspectiva brasileira. São Paulo: Atlas.

HILLIER, F. S.; LIEBERMAN, G. J. (2012) Introduction to Operations Research. Tata McGraw-Hill Education.

LACHTERMACHER, G. (2007) Pesquisa operacional na tomada de decisões: modelagem em Excel. Elsevier.

LIMA, A.; LIMA FILHO, R. C. (2010) O papel do Cespe/UnB na sociedade: processos de prestação de serviços. 
DOI: 10.14807/ijmp.v11i7.1206

LINDO SYSTEMS. LINGO: the modeling language and optimizer. http://www.lindo.com/.

MOORE, J. H.; WEATHERFORD, L. R. (2005) Tomada de decisão em administração com planilhas. Bookman.

MORESI, E. et al. (2003) Metodologia da pesquisa. Universidade Católica de Brasília.

NISHI B. S.; REIS S. A.; GUARNIERI P. (2016) Análise de trade-off entre custo e nível de serviço: estudo de caso em uma empresa no setor de distribuição de bebidas. ENEGEP.

NIXON, J. D. (2016) Designing and optimising anaerobic digestion systems: A multi-objective non-linear goal programming approach. Energy, v. 114, p. 814-822.

CEBRASPE (2016) Relatório de gestão 2016. Available: http://www.cespe.unb.br/cebraspe/arquivos/Relatorio_de_Gestao_2016.pdf. Access: 27th November, 2019.

WINSTON, W. L.; GOLDBERG, J. B. (2004) Operations research: applications and algorithms. Boston: Duxbury press.

YIN, R. K. (2010) Estudo de Caso: Planejamento e Métodos. Bookman editora. 